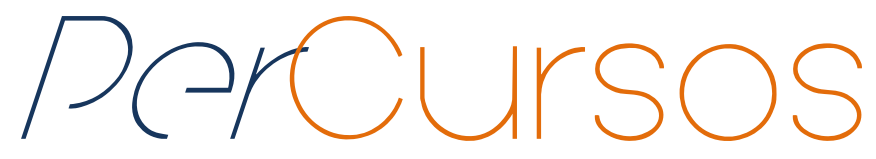

\title{
“As empregadas domésticas envelhecem?": envelhecimento populacional e o lugar social da categoria "doméstica" na força de trabalho
}

\section{Resumo}

Este artigo se volta a refletir sobre o envelhecimento em interfaces com as relações de gênero e trabalho, mostrando o envelhecimento da categoria das empregadas domésticas com base na Pesquisa Nacional por Amostra de Domicílios (PNAD) Contínua de 2013. Em termos dos processos metodológicos, este estudo é de natureza exploratório-descritiva, pautando-se na busca por explorar o tema (envelhecimento da força de trabalho) em interface com o problema da pesquisa ("As empregadas domésticas envelhecem?"). Portanto, a velhice das empregadas domésticas pelas estatísticas sugere a escassez dessa mão de obra. Dentre os fatores apontados para este envelhecimento, encontram-se: a falta de reposição geracional dessa componente força de trabalho, o aumento da expectativa de vida das mulheres, diminuição do trabalho doméstico infantil e aumento da escolarização das mais jovens que acabam tendo maiores possibilidades de inserção em outras ocupações. É nesse momento que o significado da velhice para a empregada doméstica, idosa, mulher tomam corpo, um tempo de consolidação das experiências, da libertação das obrigações e controles reprodutivos, mas, também do corpo manifestar toda uma vida de servidão.

Palavras-chave: Empregados Domésticos. Gênero. Geração. Velhice.
Guélmer Júnior Almeida de Faria

Mestre em Desenvolvimento Social pela Universidade Estadual de Montes Claros - UNIMONTES. Doutorando em Desenv. Social na UNIMONTES.

Brasil

guelmerjrf@yahoo.com.br

\section{Maria da Luz Alves Ferreira}

Doutora em Ciências Humanas pela Universidade Federal de Minas Gerais - UFMG. Professora da Universidade Estadual de Montes Claros - UNIMONTES. Brasil mdaluz@oi.com.br

\author{
Andréa Maria Narciso Rocha de \\ Paula \\ Doutora em Geografia pela \\ Universidade Federal de \\ Uberlândia - UFU. Professora \\ Universidade Estadual de Montes \\ Claros - UNIMONTES. \\ Brasil \\ andreapirapora@yahoo.com.br
}

\section{Para citar este artigo:}

FARIA, Guélmer Júnior Almeida de; FERREIRA, Maria da Luz Alves; PAULA, Andréa Maria Narciso Rocha de. "As empregadas domésticas envelhecem?": envelhecimento populacional e o lugar social da categoria "doméstica" na força de trabalho. Revista PerCursos, Florianópolis, v. 18, n.37, p. 229 - 254, maio/ago. 2017.

\section{DOI: $10.5965 / 1984724618372017229$}

http://dx.doi.org/10.5965/1984724618372017229 


\title{
“Do domestic workers age?": Population aging and the social place of the "domestic" category in the workforce
}

\begin{abstract}
This article reflects on aging at interfaces with gender and labor relations, showing the aging of the household category based on the 2013 National Continuous Household Sample Survey (PNAD). In terms of methodological processes, this study has an exploratory-descriptive nature, and seeks to explore the theme (aging of the workforce) in interface with the research problem ("Do domestic servants age?"). Therefore, the old age of domestic servants by statistics suggests the scarcity of this workforce. Among the factors pointed out for this aging are: the lack of generational replacement of this workforce component, the increase in the expectancy of women's lives, a decrease in child domestic work and an increase in the schooling of younger women who end up having more possibilities of insertion in other occupations. It is at this moment that the meaning of old age for the domestic servant, elderly and woman, takes form, being a time of consolidation of experiences, of liberation from obligations and reproductive controls, but also for a body to demand a whole life of servitude.
\end{abstract}

Keywords: Domestic Employees. Genre. Generation. Old age. 


\section{Introdução}

O trabalho doméstico sempre esteve presente no debate da sociologia do trabalho. Na contemporaneidade, tem sido abordado sob diferentes enfoques, seja pela sua heterogeneidade, provisão, externalidade ou existência. Essa força de trabalho "invisível” vem passando por transformações e mutações a cada oscilação do mercado de trabalho. Neste sentido, essa força de trabalho tem se apresentado cada vez mais velha, escolarizada e cara. Para Fernandes e Garcia (2010, p. 772):

[...] o conhecimento acumulado sobre como as pessoas envelhecem aponta a plasticidade e a diversidade como características fundamentais, mostrando que nem todos vivem o processo de envelhecimento da mesma maneira, uma vez que esse fenômeno está estreitamente relacionado às formas materiais e simbólicas que identificam socialmente cada indivíduo.

Uma das primeiras impressões dessa categoria é essa oscilação entre a intensificação e o crescimento da formalidade. Segundo Pesquisa Nacional por Amostra de Domicílios (PNAD/2015), o contingente de trabalhadores domésticos voltou a aumentar no início de 2015 no Brasil (Tabela 1).

Tabela 1 - Proporção de trabalhadores domésticos, segundo condição de ocupação. Brasil primeiro trimestre de 2014 e primeiro trimestre de 2015

\begin{tabular}{|c|c|c|}
\hline Período & Quantidade & $\begin{array}{c}\text { Percentual de } \\
\text { formalização }\end{array}$ \\
\hline Primeiro Trimestre 2015 & 6.019 milhões & $32,3 \%$ \\
\hline Primeiro Trimestre 2014 & 5.929 milhões & $31,5 \%$ \\
\hline
\end{tabular}

Fonte: Adaptado da PNAD, 2015

De acordo com Girard-Nunes e Silva (2013, p. 597), “o que mudou é que nas décadas precedentes havia um movimento de empregadas que trabalhavam frequentemente até os 49 anos e depois cuidavam dos netos/netas para as filhas 
poderem trabalhar. Havia assim uma reprodução dos lugares sociais sem mobilidade social”. De acordo com a Pesquisa Nacional de Amostra por Domicílios (PNAD), de 2013, do IBGE, percebeu-se um aumento de 68.000 trabalhadores domésticos com idade acima de 50 anos, equivalente a $0,75 \%$, ou seja, a não reposição com novas trabalhadoras na proporção daquelas que estão saindo, evidenciando o envelhecimento da força de trabalho da categoria "doméstica".

Na visão de Pinheiro, Fontoura e Pedrosa (2012),

O fato é que as pesquisas apontam para a inexistência de uma reposição geracional desta categoria, o que significa que a ocupação tem sido sustentada por um estoque de trabalhadoras que tende a se reduzir cada vez mais, seja pelo próprio aspecto demográfico, seja porque conseguem aposentar-se e retirar-se do mercado. Assim, é possível pensar que, dado o processo de envelhecimento populacional e o surgimento de novas possibilidades ocupacionais para as jovens trabalhadoras, o trabalho doméstico - da forma como conhecemos hoje - tende a se reduzir drasticamente.

Assim, o envelhecimento da população ${ }^{1}$, com maior expectativa de vida ao nascer para as mulheres em relação aos homens e, consequentemente, a presença massiva do segmento feminino na população idosa, e, finalmente, a tendência demográfica mais significativa, que tem ocorrido desde 1980, que é o crescimento acentuado de arranjos familiares chefiados por mulheres (BRUSCHINI, 2007).

A magnitude do envelhecimento das populações, nas condições objetivas de vida em que se processa para a grande maioria dos seres humanos em escala mundial, configura-se como uma das novas expressões da "velha" questão social, tendo em vista que se manifesta como reflexo da histórica luta de classes, ou seja, do antagonismo estrutural inconciliável entre capital e trabalho (PAIVA, 2014).

\footnotetext{
${ }^{1}$ Considera-se idosa a pessoa com 60 anos ou mais. Esse critério também é adotado pelo censo do Instituto Brasileiro de Geografia e Estatística (IBGE), utilizado também pelo Organização Mundial de Saúde (OMS) e pelos programas e políticas sociais com foco no envelhecimento. Contudo, há nomenclaturas diversas que dependem de outros fatores para qualificar este segmento.
} 
Para Poldi, Borges e Dalbello-Araújo (2011), as novas configurações da força de trabalho que acompanham a globalização econômica e a reestruturação produtiva colocam em cena o trabalho precarizado (economia informal nos países subdesenvolvidos, perda de direitos trabalhistas e previdenciários, salários mais baixos, etc.) como condição para a continuidade da acumulação capitalista. Entretanto, apesar da sua expansão no mercado de trabalho em geral, a precarização tem ocorrido em maior proporção entre as mulheres.

Desta forma, o trabalho doméstico retrata uma complexidade experienciada por classe, raça, gênero que se sobrepõe às dimensões do controle da vida das mulheres e à emergência das desigualdades estruturais perpetuadas. Apesar das mudanças observadas na diminuição do trabalho infanto-juvenil, da metamorfose das relações de trabalho (mensalistas que dormem no domicílio a diaristas), envelhecimento profissional da classe, redução da idade para ingresso nesta atividade, maior qualificação das mulheres, entre outras, o trabalho doméstico segundo Bernardino-Costa (2015, p. 147), "ainda continua sendo uma importante categoria ocupacional para milhares de mulheres, especialmente mulheres negras".

A servidão doméstica, no dizer de Hirata (2004, p. 44),

Parece assim refratária às grandes mutações da atividade feminina. Sua perduração interroga grandemente o campo da pesquisa e continua a ser questionada pelos movimentos feministas, dos anos setenta, às reivindicações atuais (divisão das tarefas domésticas entre homens e mulheres, valorização do trabalho doméstico, envelhecimento da categoria doméstica, etc.).

Portanto, ao refletir sobre o envelhecimento em interfaces com as relações de gênero, raça, etnia, classe social e ocupação sob diferentes contextos sociais, de modo relacional, sendo delineadores das trajetórias dos sujeitos sociais, pretende-se neste estudo mostrar o envelhecimento da categoria das empregadas domésticas com base na Pesquisa Nacional por Amostra de Domicílios (PNAD) Contínua de 2013. 


\section{Notas metodológicas}

Em termos dos processos metodológicos, este estudo é de natureza exploratóriodescritiva, pautando-se na busca por explorar o tema (envelhecimento da força de trabalho) em interface com o problema da pesquisa ("As empregadas domésticas envelhecem?”). Como caracteriza Gil (1999, p. 44), “há pesquisas que, embora definidas como descritivas a partir de seus objetivos, acabam servindo mais para proporcionar uma nova visão do problema, o que as aproxima das pesquisas exploratórias". Neste sentido, as pesquisas exploratórias requerem habitualmente um levantamento bibliográfico e as pesquisas descritivas, coleta de dados; neste estudo, entretanto, a coleta de dados é secundária, sendo utilizada a Pesquisa Nacional por Amostra de Domicílios (PNAD) Contínua do ano de 2013.

A PNAD Contínua visa produzir indicadores para acompanhar as flutuações trimestrais e a evolução, a médio e longo prazos, da força de trabalho e outras informações necessárias para o estudo e desenvolvimento socioeconômico do País. A pesquisa é realizada por meio de uma amostra probabilística de domicílios, extraída de uma amostra mestra de setores censitários, de forma a garantir a representatividade dos resultados para os diversos níveis geográficos definidos: Brasil, Grandes Regiões, Unidades da Federação e Regiões Metropolitanas que incluem os municípios das capitais (IBGE, 2014).

Entre os conceitos que merecem ser definidos neste estudo na classificação das principais características que foram objeto do artigo, destacam-se:

Empregado(a) doméstico(a) - Para a pessoa residente em domicílio particular que presta serviços domésticos remunerados a um ou mais moradores do domicílio;

Idade - A investigação da idade é feita por meio da pesquisa do dia, mês e ano de nascimento da pessoa ou da idade presumida da pessoa que não sabe a data de nascimento. A idade é calculada em relação ao último dia da semana de referência. 


\section{Condição em relação à força de trabalho:}

As pessoas são classificadas quanto à condição em relação à força de trabalho na semana de referência, como na força de trabalho e fora da força de trabalho.

Pessoas na força de trabalho - As pessoas na força de trabalho na semana de referência compreendem as pessoas ocupadas e as pessoas desocupadas nessa semana.

Pessoas fora da força de trabalho - São classificadas como fora da força de trabalho na semana de referência, as pessoas que não estavam ocupadas nem desocupadas nessa semana.

Taxa de participação na força de trabalho - É o percentual de pessoas na força de trabalho, na semana de referência, em relação às pessoas em idade de trabalhar:

[pessoas na força de trabalho / pessoas em idade de trabalhar] x 100

\section{Envelhecimento das Empregadas Domésticas: aspectos demográficos e} sociais

As mulheres idosas são maioria em todas as sociedades envelhecidas; Belo (2013) aponta que no Brasil, compõem 55,8\%, a preponderância das mulheres neste contingente populacional revela a feminização da velhice, processo que exige ações e políticas públicas para a idosa, considerando, por um lado, as particularidades de sua realidade e, por outro, a permanência e a intensificação das desigualdades de gênero.

A transição demográfica demarcada por Cerqueira (2003) aponta que os idosos são a parcela da população que mais está crescendo em quase todos os países do mundo, e no Brasil não é diferente. Dado o processo de declínio rápido e generalizado da fecundidade, temos uma pirâmide etária com base estreita, ou seja, a proporção de crianças na população diminuiu e, consequentemente, o peso relativo de todas as demais faixas etárias sofreu aumentos significativos.

Paiva (2014) chama atenção para os fatores a serem considerados no tocante à transição demográfica em curso no país: a feminização, a urbanização e heterogeneidade 
do envelhecimento populacional. Esses eventos situam o Brasil, no início do século XXI, como um país com padrão demográfico semelhante ao de países desenvolvidos (Tabela 2)

Tabela 2 - Características demográficas. Brasil, período 2000 e projeção 2050

\begin{tabular}{|c|c|c|c|}
\hline Período & $\begin{array}{c}\text { Proporção de } \\
\text { homens/mulheres }\end{array}$ & $\begin{array}{c}\text { População } \\
\text { feminina idosa }\end{array}$ & Esperança de vida \\
\hline 2000 & $97 / 100$ mulheres & 2,5 milhões & $\begin{array}{c}66,71 \text { anos (homens) } \\
74,29 \text { anos (mulheres) }\end{array}$ \\
\hline 2050 & $95 / 100$ mulheres & 6 milhões & $\begin{array}{c}78,2 \text { anos (homens) } \\
84,5 \text { anos (mulheres) }\end{array}$ \\
\hline
\end{tabular}

Fonte: Adaptado da PNAD, 2013

Se, por um lado, as estatísticas mostram que as mulheres idosas podem aspirar viver mais anos do que os homens, por outro, denotam maior demanda por cuidados com impactos importantes na prossecução de políticas públicas. Motta (2011, p. 15) diz que

essas trajetórias de vida tão diversas, quase paralelas, raras vezes confluentes, somente quando velhos têm encontrado destinos e situações mais assemelhados - aproximados pelo preconceito e pelo cerceamento social - porém jamais idênticas, em situações sempre nuançadas pela condição de gênero.

E em relação ao processo de urbanização do envelhecimento, o IBGE (2000) destaca que "a proporção de idosos residentes nas áreas rurais passou de 23,3\%, em 1991, para 18,6\%, em 2000. O grau de urbanização da população idosa acompanhou a tendência da população total, ficando em torno de 81\% em 2000". Uma das consequências geradas pelo processo migratório marcado por um país com passado agrário, o que afeta a organização social dos grandes centros urbanos e ocasiona problemas psicológicos nas pessoas idosas. 
Paiva (2014) evidencia que esse processo causará impacto considerável na demanda por políticas públicas, visto que, embora as mulheres vivam mais do que os homens, elas estão mais sujeitas às deficiências físicas e mentais.

O modelo de velhice ativa, adotado por muitos países em desenvolvimento, de acordo com Belo (2013), omite as desigualdades estruturais dos grupos com maiores dificuldades (principalmente as mulheres e, em especial, as de baixa renda, como empregadas domésticas). Não há dúvida de que as pessoas idosas representam um grupo de população com maior vulnerabilidade física, com maior probabilidade de enfrentar situações de dependência em meio a um contexto de carência de serviços sóciosanitários.

Em relação ao trabalho, Hirata (2009), assinala que o crescimento contínuo da taxa de atividade das mulheres nos últimos trinta anos, acarretou sua presença maciça e irreversível no trabalho assalariado, e reforçou e redefiniu seu lugar nas questões levantadas pelas Ciências Sociais. Ela ainda aponta que as mulheres se situam no foco do debate francês sobre a precarização do trabalho, em função das modalidades particulares de aplicação da flexibilidade do trabalho.

As questões relativas ao envelhecimento dos trabalhadores têm recebido uma especial atenção por parte das ciências sociais nas últimas décadas no Brasil. Algumas categorias de trabalhadores, no entanto, têm sido pouco contempladas por este debate, em virtude, talvez, da própria "inferioridade" a qual parecem estar condenadas. Este parece ser o caso das empregadas domésticas, uma categoria de trabalhadoras cujas especificidades em relação às questões de força de trabalho e de proteção previdenciária permanecem tão invisíveis quanto seu próprio trabalho (TAMANINI, 2000).

Wajnman (2016) destaca a relação entre dinâmica demográfica e desigualdade sob o ângulo da composição populacional por sexo como fator central para a expansão e a consolidação, nas últimas décadas, da participação feminina no mercado de trabalho. Logo, já é possível observar um acentuado processo de envelhecimento dessa força de trabalho. Nas últimas décadas, a média de idades das trabalhadoras domésticas cresceu de 35 anos para 39 anos. 
Para Fraga (2010), enquanto houve uma diminuição significativa das quatro primeiras faixas de idade, de 10 a 29 anos, houve um aumento das três últimas, de 30 a mais de 60 anos. Tal processo está relacionado ao envelhecimento da população brasileira como um todo.

Em consequências desse envelhecimento, Cerqueira (2003) sinaliza que o ganho de longevidade ou o acréscimo no número de anos vividos por um indivíduo pode implicar em aumento da morbidade e em um conjunto maior de pessoas vivendo em condições de saúde pouco favoráveis, com algum tipo de incapacidade.

Assim, Cerqueira (2003) complementa dizendo que é sabido que existem freios biológicos para a vida humana e o aumento da esperança de vida implica na emergência de um padrão de morte natural, ao fim de um espectro natural de vida. Há o aumento drástico e catastrófico da ocorrência de distúrbios mentais e doenças crônicodegenerativas em idosos, e esse novo cenário é visto com preocupações por acarretar mudanças no perfil das demandas por políticas públicas, colocando desafios para o Estado, a sociedade e a família. Quando se analisa sob o prisma do trabalho doméstico, essas transformações ganham peso ainda maior.

Tamanini (2000), ao analisar o processo de saúde e doença das empregadas domésticas, encontrou nesta experiência, carregada de desconfortos e angústia, em alguns momentos, pequenas brechas de descontentamento diante da condição a que se sentem relegadas, e se acirram quando a consciência traz à tona a limitação a que suas vidas estão sendo submetidas.

Em relação à condição de gênero, Tamanini (2000) refere-se à relação de trabalho como desencadeadora de situações doentias, ligadas à angústia existencial do sentimento de uma vida vazia pela escassez de sentido ou vazia pelo assimilar constante dos sentidos negativos que são construídos ao redor dessa relação.

Logo, Fernandes e Garcia (2010) explicitam seus pressupostos na abordagem da velhice sob a perspectiva de gênero, outras variáveis se encontram interpostas e, como tal, influenciam a natureza do processo de envelhecimento de homens e mulheres, isto é, o sexo, as características hereditárias, o grau de educação, o status, a cultura e a 
profissão também são condições que permeiam a individualidade da pessoa idosa, não permitindo, assim, que se estabeleça um modelo padrão para a experiência da velhice. Há, assim, a "bricolagem” de diferentes modelos de vivência desse fenômeno.

Para as empregadas domésticas, que mantêm comportamento servil, a velhice se reveste de caráter negativo, ao comprometer boa parte de sua vitalidade no trabalho. Como caracteriza Tamanini (2000), a exigência das tarefas é um dos agentes estressantes que se coloca, determinando uma sobrecarga qualitativa na relação de trabalho. Trata-se da representação das cargas psíquicas definidas enquanto desgosto, sentimento de escravidão, vergonha, sentimento de inutilidade, estresse, tristeza, melancolia, vazio, nervosismo, tensão, revolta, desconfiança, decepção, humilhação, culpa, desespero, desvalorização e submissão, quase sempre associados. As relações de trabalho com a patroa, veiculadas pela afetividade muito mais do que pelo contrato de trabalho ou pela exigência física da tarefa.

Por fim, Fernandes e Garcia (2010) exemplificam que existem vários fatores envolvidos na diversidade e expressão de heterogeneidade em relação à velhice. Dentre eles, os mais básicos estão ligados ao gênero, à família, ao trabalho e às gerações. $E$ as empregadas domésticas pesam sobre elas todo o ranço histórico de uma categoria inviabilizada do ponto de vista das relações legalistas do trabalho e de caráter ad infinitum ${ }^{2}$, em que o envelhecimento demarca a intersecção de várias categorias a sobrepor mais uma: a velhice, demarcando o lugar e a posição desse sujeito social no tempo e no espaço.

O lugar social e o significado que o trabalho assume, segundo Sá e Wanderbroocke (2016), contribui para a sobrevivência, desenvolvimento pessoal, adaptação, instrumento de realização e centralidade na vida das pessoas. Para as empregadas domésticas, pode justificar a dificuldade em aposentar-se, bem como de encontrar um espaço social para si.

Embora Motta (1999) expresse que autoafirmar-se no cotidiano é a primeira forma de diferenciação da velhice segundo os gêneros e as classes sociais, as mulheres, voltadas desde o início à domesticidade e ao cotidiano, e alguns dos mais pobres, que não têm

\footnotetext{
${ }^{2}$ Sem limite no tempo ou no espaço; indefinidamente.
} 
quem os proteja ou os substitua em tarefas e na provisão da família, têm permanecido mais ativos. E reconhecem-se assim. Declaram-se vigorosos, saudáveis e independentes, principalmente as mulheres.

Consoante a este estudo, Cerqueira (2003) chama atenção para as mudanças em curso, uma fase de transformações na sociedade em que os valores estão tendendo, cada vez mais, para um individualismo e ausência de solidariedade entre os grupos sociais. Os segmentos populacionais que atingem a velhice vão sendo marginalizados nesse processo, e aqueles indivíduos que não têm boas condições de saúde e autonomia, ou uma renda capaz de suprir as necessidades provenientes da incapacidade laboral.

No caso das empregadas domésticas, a situação é inquietante devido à capacidade de proteção social neste segmento ser menor. Hirata (2009, p. 26), evidencia que um dos indicadores do trabalho precário é:

Ausência de proteção social e de direitos sociais, inclusive de direitos sindicais: o trabalho informal nos países do Sul concerne a atividades realizadas sem proteção social (previdência social, aposentadoria), férias, etc. O mesmo ocorre com um certo número de empregos do setor de serviços nos países do Norte (trabalhadores domésticos, faxineiras, etc.).

Conquanto, como evidenciam Girard-Nunes e Silva (2013), tem havido conquistas com a aprovação da PEC das Domésticas ${ }^{3}$, que as equiparou aos demais trabalhadores e Ihes concedeu direitos de cunho protetivo e garantista, como: carteira de trabalho assinada, recebimento de ao menos um salário mínimo, sendo este irredutível, recebimento do $13^{\circ}$ salário, desfrute de repouso semanal remunerado, definição da jornada de trabalho, gozo de férias anuais remuneradas com um terço a mais do que o salário normal, garantia de estabilidade até o quinto mês após o parto e de licençamaternidade, além do cumprimento do aviso prévio e recebimento devido da

\footnotetext{
${ }^{3}$ Com a aprovação da Emenda Constitucional (PEC) n. 66/2012 em 26 de março de 2013 e publicação no Diário Oficial da União (DOU) em 3 de abril de 2013, os empregados domésticos foram contemplados quase que plenamente pelo artigo $7^{\circ}$ da Constituição Federal de 1988 e tiveram seus direitos equiparados aos trabalhadores de outras profissões, corrigindo, assim, uma injustiça social. Além do mais, de acordo com o Decreto n. 6.481, de 12 de julho de 2008, é proibido o emprego do menor de 18 anos no trabalho doméstico, por ser considerado insalubre e perigoso.
} 
aposentadoria. Apesar de suas conquistas de direitos estarem acontecendo lentamente desde a década de 1970, somente em 2013 é que se promulgou uma política pública, pois elas não são acompanhadas automaticamente pela efetivação destes direitos, com grande parcela das empregadas ainda desprotegidas.

Portanto, Hirata (2009) conclui que as mulheres constituem, com certeza, a categoria que convém considerar inicialmente, em razão do lugar singular que ocupam entre os assalariados de hoje. A definição dessa categoria, transversal àquela das categorias socioprofissionais, é evidentemente diferente daquela do grupo operário, no qual elas também estão presentes, embora em minoria; em contrapartida, são majoritárias no comércio e nos serviços (cuidadoras, trabalho doméstico, diaristas, etc.). A precarização do trabalho que atinge a categoria dos empregados deve ser então correlacionada à sua composição sexuada.

Neste sentido, conhecer os números dessa força de trabalho aponta para alguns fatos importantes para a categoria, entre conquistas, avanços e o futuro, que serão examinados a seguir.

\section{O que dizem os dados sobre a força de trabalho "Doméstica"?}

Nesta seção, serão tratados dados da componente feminina inserida no trabalho doméstico com base na PNAD $/ 2013^{4}$ referentes a idade, sexo, força de trabalho (ocupada e não ocupada). A proporção de mulheres no emprego doméstico vem caindo lentamente ao longo dos últimos anos. O dado mais recente disponível mostra que, em 2014, 14\% das brasileiras ocupadas eram trabalhadoras domésticas, um total de 5,9 milhões (Tabela 3).

Aqui, a diferença racial é marcante: $17,7 \%$ das mulheres negras eram trabalhadoras domésticas, ainda a principal ocupação entre elas, ao passo que, entre as brancas, 10\%

\footnotetext{
4 PNAD Contínua: A população alvo é constituída por todas as pessoas residentes em domicílios particulares permanentes da área de abrangência da pesquisa. Um domicílio é entrevistado em um mês, permanece os dois meses seguintes fora da amostra e retorna para a próxima entrevista. O processo se repete até que ele seja entrevistado cinco vezes. Em síntese, um domicílio é entrevistado durante cinco trimestres, uma vez a cada trimestre.
} 
estavam no emprego doméstico, que há décadas não constitui o setor de atividade econômica que mais emprega brancas, ficando atrás do comércio e da indústria. (PINHEIRO et al., 2016).

Tabela 3 - Proporção de trabalhadoras domésticas entre as mulheres ocupadas de 10 anos ou mais de idade, segundo cor/raça. Brasil, 2004 a 2014

\begin{tabular}{|c|c|c|c|}
\hline Ano & Brancas & Negras & Total \\
\hline 2004 & $13,5 \%$ & $21,5 \%$ & $17,1 \%$ \\
\hline 2014 & $10,1 \%$ & $17,7 \%$ & $14,0 \%$ \\
\hline
\end{tabular}

Fonte: Adaptado de Pinheiro et al., 2016

Essa racialização do trabalho doméstico é apontada por Girard-Nunes e Silva (2013); os dados mostram que entre 2004 e 2011 houve um aumento da participação das mulheres negras nos serviços domésticos, de 56,9\% para $61 \%$. Quanto à faixa etária, percebe-se que a proporção de jovens ocupadas nos serviços domésticos tem caído, passando de 6,1\% para 3,9\%, para aquelas entre 10 e 17 anos; e, de 16,8\% para 9,3\%, entre 18 e 24 anos de idade.

Quando feito o cruzamento entre faixa etária e raça, é possível perceber que há uma redução na participação das mulheres negras até 29 anos, de 39,8\%, em 2004, para 25,3\%, em 2011, e um aumento da participação das mulheres negras acima de 40 anos de idade, de $33,7 \%$ para $47 \%$.

Esses dados mostram que tem aumentado consideravelmente a participação de mulheres negras, especialmente as de meia idade. Entre as jovens, mesmo as negras, sua participação tem diminuído, possivelmente em decorrência da melhor qualificação e das novas oportunidades surgidas entre os anos de 2007 e 2011, período de forte crescimento econômico no Brasil.

Constata-se que o envelhecimento da categoria ocorreu de forma mais acelerada para as negras do que em relação às brancas. Em tese, justifica-se pela maior 
oportunidade das jovens brancas de migrarem para outro segmento ocupacional, deixando o trabalho doméstico como inserção profissional ou como forma de manter-se no mercado de trabalho.

Hirata (2016), analisando o trabalho do cuidado em domicílios, apontou uma ambiguidade profissional ou interposição de duas categorias: empregadas domésticas e cuidadoras. De um grupo de 29 mulheres empregadas domésticas, identificadas, elas declararam trabalhar tanto como empregadas da casa quanto como cuidadoras de idosos. Foram 12 as mulheres que se identificam como cuidadoras, sem fazer referência ao trabalho doméstico remunerado.

Esses dados prospectam e até elevam a subestimação da força de trabalho da categoria “doméstica”, quando se pensa o trabalho doméstico em domicílio. Hirata (2016) diz que é impossível pensar o mercado de trabalho para as atividades do cuidado, no Brasil, sem considerar a existência de uma fluidez de fronteiras que obscurece os limites entre trabalho de cuidado para pessoas dependentes e trabalho doméstico remunerado tradicional.

Em relação ao sexo, do conjunto de mulheres ocupadas em 2013, 92,7\% - 5.950.000 de mulheres - tinham o trabalho doméstico como principal fonte de renda (Tabela 4). E os homens representavam $7,3 \%$ dessa força de trabalho, ou seja, 473.000 mil homens.

Tabela 4 - Proporção de trabalhadores domésticos por sexo

\begin{tabular}{|c|c|c|}
\hline Sexo & Quantidade & Percentual \\
\hline Feminino & 5.950 .000 & $92,7 \%$ \\
\hline Masculino & 473.000 & $7,3 \%$ \\
\hline Total & 6.423 .000 & $100 \%$ \\
\hline
\end{tabular}

Fonte: Adaptado da PNAD, 2013

Pela abordagem de gênero, Bruschini (2007) já sinalizava o trabalho doméstico, ou seja, o emprego doméstico remunerado como o nicho ocupacional feminino por 
excelência, no qual mais de 90\% dos trabalhadores são mulheres. Ele se manteve como importante fonte de ocupação, praticamente estável, absorvendo $17 \%$ da força de trabalho. Esse percentual tem diminuído no tempo, uma vez que em 1970, absorvia mais de 1/4 da força de trabalho feminina (BRUSCHINI; LOMBARDI, 2000).

A ocupação de trabalhadora doméstica ainda representa nos dias de hoje oportunidade de colocação para mais de seis milhões de mulheres no mercado de trabalho brasileiro, sendo considerada precária em razão das longas jornadas de trabalho desenvolvidas pela maioria das trabalhadoras, pelo baixo índice de posse de carteira de trabalho (apenas 25\% delas) e pelos baixos rendimentos auferidos (96\% ganham até dois salários mínimos) (BRUSCHINI, 2007).

Em oposição a essas tendências recentes no trabalho profissional feminino, as mudanças no trabalho doméstico são menores e muito mais lentas. Se o forte desenvolvimento das tecnologias domésticas tendeu a facilitar essas tarefas, a divisão sexual do trabalho doméstico e a atribuição deste último às mulheres, em realidade, continuou intacta (HIRATA, 2002).

De acordo com Pinheiro, Fontoura e Pedrosa (2012), ao longo do período de estudo, é possível identificar outro fenômeno interessante no grupo das trabalhadoras domésticas: o envelhecimento deste segmento, com a queda proporcional nas faixas etárias mais jovens - especialmente até 24 anos - e um aumento entre as mais velhas (Tabela 5).

Tabela 5 - Proporção de trabalhadores domésticos por idade

\begin{tabular}{|c|c|c|}
\hline Idade & Quantidade & Percentual \\
\hline $15-17$ anos & 163.000 & $2,4 \%$ \\
\hline $18-19$ anos & 110.000 & $1,71 \%$ \\
\hline $20-24$ anos & 357.000 & $5,56 \%$ \\
\hline $25-29$ anos & 501.000 & $7,80 \%$ \\
\hline $30-39$ anos & 1.711 .000 & $26,64 \%$ \\
\hline
\end{tabular}




\begin{tabular}{|c|c|c|}
\hline $40-49$ anos & 1.918 .000 & $29,86 \%$ \\
\hline $50-59$ anos & 1.228 .000 & $19,12 \%$ \\
\hline 60 anos ou mais & 435.000 & $6,77 \%$ \\
\hline Total & 6.423 .000 & $100 \%$ \\
\hline
\end{tabular}

Fonte: Adaptado da PNAD, 2013

Com a redução do trabalho doméstico infantil ${ }^{5}$ e a abertura de outras oportunidades de emprego para as jovens mulheres, as trabalhadoras com idade acima de 30 anos passam a ter cada vez mais importância neste grupo. De fato, enquanto em 1999 este grupo respondia por 56,5\% do total de trabalhadoras domésticas, em 2009 este valor saltou para impressionantes $72,7 \%$, sendo que, neste ano, as trabalhadoras com 45 anos ou mais respondiam sozinhas, por mais de $30 \%$ da categoria.

Em 2013, as mulheres com idade acima de 30 anos correspondiam a 26,64\%, as de 40 anos 29,86\% e as de 50 anos, 19,12\%. De acordo com Pinheiro, Fontoura e Pedrosa (2012), o fato é que os dados apontam para a inexistência de uma reposição geracional desta categoria, o que significa que a ocupação tem sido sustentada por um estoque de trabalhadoras que tende a reduzir cada vez mais, seja pelo próprio aspecto demográfico, seja porque conseguem aposentar-se e retirar-se do mercado.

A taxa de ocupação, por sexo, nas cinco regiões do Brasil, aponta uma queda do nível de ocupação das mulheres em relação aos homens (Tabela 6). Para Alves (2013), devido à divisão sexual do trabalho, as mulheres continuam com menor inserção no mercado de trabalho remunerado e maior presença no trabalho doméstico não remunerado.

Alves (2013) completa dizendo que o nível de inserção de ambos os sexos na população economicamente ativa, e o aumento da participação feminina no mercado de

\footnotetext{
50 trabalho doméstico infantil - entre crianças e jovens de até 17 anos - é considerado pelo Decreto $\mathrm{n}_{-}^{\circ}$ 6.481 de 2008, que regulamenta a Convenção $n^{\circ} 182$ da Organização Internacional do Trabalho (OIT), como uma das piores formas de trabalho infantil, sendo seu exercício, portanto, proibido em território nacional (BRASIL, 2008).
} 
trabalho não eliminou os problemas de segregação ocupacional e discriminação salarial, embora tenham sido abrandados.

TABELA 6 - Nível da ocupação, na semana de referência, das pessoas de 14 anos ou mais de idade, por sexo, segundo as Grandes Regiões - $2^{\circ}$ trimestre de 2013

\begin{tabular}{|c|c|c|c|}
\hline Região & Masculino & Feminino & Total \\
\hline Centro-Oeste & $73,5 \%$ & $49,7 \%$ & $61,3 \%$ \\
\hline Sul & $71,9 \%$ & $52,1 \%$ & $61,6 \%$ \\
\hline Sudeste & $69,9 \%$ & $48,5 \%$ & $58,6 \%$ \\
\hline Nordeste & $63,2 \%$ & $39,0 \%$ & $50,5 \%$ \\
\hline Norte & $70,6 \%$ & $43,6 \%$ & $56,9 \%$ \\
\hline Brasil & $68,7 \%$ & $46,2 \%$ & $56,9 \%$ \\
\hline
\end{tabular}

Fonte: Adaptado da PNAD, 2013

Do ponto de vista de Wajnman (2016), as mulheres continuam enfrentando sérias dificuldades para se inserir no mercado de trabalho em condições semelhantes às dos homens. Além das diferenças salariais, as taxas de desemprego femininas tendem a ser, sistematicamente, superior às dos homens. Mas o aspecto mais evidente dos diferenciais em condições de inserção no mercado de trabalho é a questão da segregação ocupacional que concentra homens e mulheres em diferentes tipos de ocupação, emprego e local de trabalho.

Neste caso, o trabalho doméstico. Isso não seria exatamente um problema se não fosse pelo fato de que os tipos de ocupações nos quais estão concentradas as mulheres tendem a ser de pior qualidade, o que pode significar piores salários, menor proteção da legislação trabalhista e previdenciária e menos perspectivas de mobilidade ascendente nas carreiras.

De acordo com a Pesquisa de Emprego e Desemprego (PED/2015), percebem-se mudanças crescentes na inserção dos trabalhadores domésticos nos mercados de trabalho regionais, ainda que não se possam distinguir, com precisão, quantas delas 
decorrem da aprovação da Emenda Constitucional n 72, de abril de 2013 (PEC das Domésticas), e o quanto são determinadas pelos movimentos da conjuntura econômica do país. A categoria, por sua vez, quantitativamente relevante, é caracterizada por ainda ser uma das mais importantes alternativas de inserção ocupacional feminina na sociedade brasileira.

Dados do IBGE (2016) revelam que em abril de 2016 havia 6.294 .505 de trabalhadores domésticos. Nesse cenário pós-implantação da PEC das domésticas em março de 2016, os trabalhadores domésticos com registro em carteira eram 2.169.529 e os que ainda se encontravam na informalidade somavam 4.050.975. Se compararmos com o período anterior à PEC, em maio de 2015, quando o registro em carteira era de 1.917.267 contra 4.083.991 sem registro em carteira.

Outro aspecto a ser considerado em relação à força de trabalho feminina é a distribuição entre homens e mulheres fora da força de trabalho (Tabela 7). As regiões que apresentam maior taxa de mulheres fora da força de trabalho são Centro-Oeste e Norte do país. Consequentemente, a região em que a desocupação é menor é no Sul.

De fato, este dado requer uma maior explicitude em virtude de não se considerar o trabalho doméstico não remunerado, e que o conceito de atividade abrange tão somente uma atividade que contribui para a produção e reprodução da vida e que gera valor, consubstanciando na informalidade em que pesa a grande maioria das ocupações femininas.

Como é percebido no discurso da sociedade uma desvalorização do espaço doméstico, que na visão de Sá e Wanderbroocke (2016) é tido como um espaço pouco estimulante e que não produz rendimentos. A construção social contemporânea do trabalho doméstico o destaca como desvalorizado socialmente por ser normalmente desempenhado por mulheres, visto como não trabalho, por ser não remunerado e invisível, além de ser uma tarefa repetida e desfeita continuamente.

Pinheiro, Fontoura e Pedrosa (2012) exemplificam que é preciso investigar mais a fundo o perfil das mulheres tidas como inativas, de modo que se possa entender as 
barreiras que as separam do mercado de trabalho e para que as políticas desenvolvidas sejam mais efetivas no sentido de reverter tão grande desigualdade.

Tabela 7 - Distribuição das pessoas de 14 anos ou mais de idade, fora da força de trabalho, na semana de referência, por sexo, segundo as Grandes Regiões $-2^{\circ}$ trimestre de 2013

\begin{tabular}{|c|c|c|}
\hline Região & Masculino & Feminino \\
\hline Centro-Oeste & $31,9 \%$ & $68,1 \%$ \\
\hline Sul & $34.4 \%$ & $65,5 \%$ \\
\hline Sudeste & $33,2 \%$ & $66,8 \%$ \\
\hline Nordeste & $33,5 \%$ & $66,5 \%$ \\
\hline Norte & $32,0 \%$ & $68,0 \%$ \\
\hline Brasil & $33,3 \%$ & $66,7 \%$ \\
\hline
\end{tabular}

Fonte: Adaptado da PNAD, 2013

Wajnman (2016) corrobora dizendo que as evidências extremamente desfavoráveis à criação de novos empregos, sugerem que o espaço da informalidade, sobretudo no comércio de mercadorias e no emprego doméstico, foram as principais vias de acesso das mulheres ao mercado de trabalho.

As empregadas domésticas enfrentam condições ocupacionais e salariais mais precárias, sobretudo quando estas ocupam a posição de chefia de suas famílias. Como as condições laborais refletem-se diretamente nos benefícios da previdência social, e como as idosas encontram maiores dificuldades para se manterem economicamente ativas, os diferenciais por sexo tornam-se ainda mais marcantes na velhice (WAJNMAN, 2016).

Logo, as mulheres na velhice experimentariam, segundo Debert (1994), uma situação de dupla vulnerabilidade com o peso somado de dois tipos de discriminação: enquanto mulher e enquanto idosa. Sendo a mulher em quase todas as sociedades valorizada exclusivamente por seu papel reprodutivo e pelo cuidado das crianças, o desprezo e o isolamento marcariam sua passagem prematura à velhice. Essa passagem antes de ser contada pela referência cronológica seria marcada por uma série de eventos 
associados a perdas, como o abandono dos filhos adultos a viuvez ou o conjunto de transformações físicas trazidas pelo avanço da idade. Nas sociedades ocidentais contemporâneas, a esse conjunto de perdas, deve se somar o subemprego, os baixos salários, o isolamento e a dependência que caracterizariam a condição das mulheres de mais idade.

Em alguns casos, segundo dados de Camarano e Kanso (2010), nas Instituições de Longa Permanência (ILPIs) pesquisadas residiam cerca de 100 mil pessoas, das quais 84 mil eram idosas, o que representa menos de $1 \%$ da população idosa brasileira. As mulheres predominam (57,3\%) entre os residentes. Importante, considerar o perfil dessas idosas e suas trajetórias. Quantas dessas mulheres em algum momento da sua vida, trabalhou como empregada doméstica? Parcial ou integralmente? Por quantos anos? Questões como essas, só poderão ser respondidas através de pesquisas qualitativas e pontuais sobre o papel social dessas idosas.

Assim, em meio às transformações e às mutações do trabalho dentro do cenário da reestruturação produtiva, em que pesa sob o trabalhador o desemprego estrutural, a precarização do trabalho e o crescimento do setor informal, com perda de direitos trabalhistas e previdenciários, historicamente conquistados ou que estão por ser conquistados, essa categoria da força de trabalho, as “domésticas”, carregam a complexidade das relações entre gênero e trabalho, e está diretamente inter-relacionada ao processo de envelhecimento, adquirindo relevância tanto por seus efeitos sobre o corpo, como por suas repercussões sobre o imaginário, carregado sempre de conteúdo negativo (TAMANINI, 2000; WAJNMAN, 2016).

\section{Considerações Finais}

Este artigo contemplou o envelhecimento da força de trabalho "doméstica". Consideramos que as análises favorecem o esclarecimento para tratar de um aspecto relevante do contexto do mercado de trabalho feminino brasileiro que se vincula ao processo de velhice das empregadas domésticas. 
Dentre os fatores apontados para este envelhecimento, encontram-se: a falta de reposição geracional dessa componente da força de trabalho, o aumento da expecatativa de vida das mulheres, diminuição do trabalho doméstico infantil e aumento da escolarização das mais jovens que acabam tendo maiores possibilidades de inserção em outras ocupações, tais como as operadoras de telemarketing e comércio.

Importante destacar que mesmo sendo uma profissão com elevado grau de desigualdade estruturante, ainda é uma das que mais absorve a força de trabalho feminina, concentrando a maior parte das mulheres negras. Embora, o Brasil tenha caminhado para a formalização do trabalho doméstico, este ainda tem demandas que são para além da igualdade de direitos com as demais categorias urbanas, mas, uma equiparação de justiça social.

Portanto, o envelhecimento das empregadas domésticas, pelas estatísticas, sugere a escassez dessa força de trabalho. Essa extinção do trabalho doméstico é fruto de maiores oportunidades para as jovens mais pobres que têm tido acesso à escolaridade. Entretanto, mesmo com a queda dessa força de trabalho, a demanda pelo serviço ainda é alta. Verifica-se em algumas capitais o aumento dos rendimentos das domésticas e o alto preço pago pelos serviços das diaristas (modalidade sem formalização contratual).

Para as empregadas domésticas esse envelhecimento é a manifestação de uma das configurações do trabalho mais complexas dentro da sociologia do trabalho - que é o trabalho doméstico. Por um lado, a lógica das relações pessoais, afetivas e familiares e de outro, a lógica das relações profissionais, contratuais e legais. É nesse momento que o significado da velhice para a empregada doméstica, idosa, mulher, tomam corpo; um tempo de consolidação das experiências, da libertação das obrigações e controles reprodutivos, mas, também do corpo manifestar toda uma vida de servidão.

Finalmente, a resposta para a pergunta se "As empregadas domésticas envelhecem?", é sim. A velhice tem distintas formas de ser vivenciada, embora a sociedade demarque o lugar social para os idosos, ela vem percebendo a exponencialidade e as potencialidades desses sujeitos sociais e eles fazem parte desse 
movimento, seja por meio dos aspectos econômicos (mercado para idosos), culturais (valorização de culturas antigas) ou sociais (políticas públicas). Assim, a pergunta que se coloca para futuros estudos é: Qual a percepção de velhice para empregadas domésticas? Qual o lugar social da empregada doméstica idosa?

\section{Referências}

ALVES, José Eustáquio Diniz. $O$ crescimento da PEA e a redução do hiato de gênero nas taxas de atividade no mercado de trabalho. 2013. Disponível em:

<http://www.ie.ufrj.br/aparte/pdfs/artigo_112_a_reducao_do hiato_de_genero_nas taxa s_de_atividade_no_mercado_de_trabalho.pdf>. Acesso em: 12 jul. 2016.

BELO, Isolda. Velhice e mulher: vulnerabilidades e conquistas. Revista Feminismos, v. $1, \mathrm{n}^{\circ}$ 3 Set./Dez. 2013.

BERNARDINO-COSTA, Joaze. Decolonialidade e interseccionalidade emancipadora: a organização política das trabalhadoras domésticas no Brasil. Revista Sociedade e Estado, v. 30, n 1, p. 147-163, jan./abr., 2015.

BRASIL. Decreto n.6.481, de 12 de junho de 2008. Regulamenta os artigos $3^{\circ}$, alínea "d", e $4^{\circ}$ da Convenção 182 da Organização Internacional do Trabalho (OIT) que trata da proibição das piores formas de trabalho infantil. Brasília: Seando, 2008. Disponível em: <http://www.planalto.gov.br/ccivil_03/_Ato2007-2010/2008/Decreto/D6481.htm>. Acesso em: 09 jun. 2016.

BRUSCHINI, Maria Cristina Aranha. Trabalho e gênero no Brasil nos últimos dez anos. Cadernos de Pesquisa, v. 37, n. 132, set./dez. 2007.

BRUSCHINI, Cristina; LOMBARDI, Maria Rosa. A Bipolaridade do trabalho feminino no Brasil contemporâneo. Cadernos de Pesquisa, nº 110, p.67-104, jul. 2000.

CAMARANO, Ana Amélia; KANSO, Solange. As instituições de longa permanência para idosos no Brasil. Revista Brasileira de Estudos Populacionais, São Paulo, v. 27, nº 1, p. 232235, jun. 2010.

CERQUEIRA, Marília Borborema Rodrigues. Envelhecimento populacional e população institucionalizada - um estudo de caso dos asilos do município de Montes Claros-MG. 2003, 109 fls. Dissertação (Mestrado em Demografia) - Universidade Federal de Minas Gerais, Faculdade de Ciências Econômicas, Centro de Desenvolvimento e Planejamanento Regional (CEDEPLAR), Belo Horizonte, 2003. 
DEBERT, Guita Grin. Gênero e envelhecimento. Estudos Feministas, v. 1, ano 2, p. 33-51, 1994 .

FERNANDES, Maria das Graças Melo; GARCIA, Loreley Gomes. O Sentido da velhice para homens e mulheres idosos. Saúde Sociedade, São Paulo, v. 19, n. ${ }^{\circ}$ 4, p.771-783, 2010.

FRAGA, Alexandre Barbosa. De empregada a diarista: as novas configurações do trabalho doméstico remunerado. 2010, 194 fls. Dissertação (Mestrado em Sociologia) -

Universidade Federal do Rio de Janeiro - UFRJ, Rio de Janeiro, 2010.

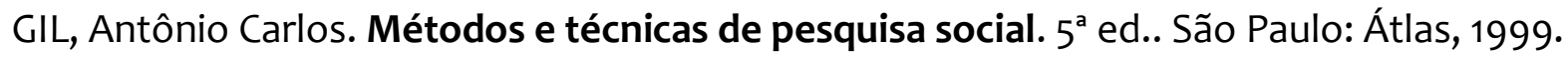

GIRARD-NUNES, Christiane.; SILVA, Pedro Henrique Isaac. Entre o prescrito e o real: o papel da subjetividade na efetivação dos direitos das empregadas domésticas no Brasil. Revista Sociedade e Estado, v. 28, n. ${ }^{\circ}$ 3, set./dez. 2013.

HIRATA, Helena. O cuidado em domicílio na França e no Brasil. IN: ABREU, A. R. P; HIRATA, H.; LOMBARDI, M. R. (Org.). Gênero e trabalho no Brasil e na França: perspectivas interseccionais. São Paulo: Boitempo, 2016.

HIRATA, Helena. A precarização e a divisão internacional e sexual do trabalho. Sociologias, n. $^{\circ} 21$, p. 24-41, 2009.

HIRATA, Helena. Trabalho doméstico: uma servidão "voluntária"?. IN: GODINHO, T., SILVEIRA, M. L. Políticas públicas e igualdade de gênero. São Paulo: Coordenadoria Especial da Mulher, 2004.

HIRATA, Helena. Globalização e divisão sexual do trabalho. Cadernos Pagu, n. ${ }^{0}$ 17-18, p. 140-156, 2002.

INTITUTO BRASILEIRO DE GEOGRAFIA E ESTATÍSTICA. Pesquisa Nacional por Amostra de Domicílios Contínua. Notas Metodológicas. V. 1, Rio de Janeiro: IBGE, 2014.

INTITUTO BRASILEIRO DE GEOGRAFIA E ESTATÍSTICA. Síntese de Indicadores. Rio de Janeiro: IBGE, 2016. Disponível em:< http://brasilemsintese.ibge.gov.br/trabalho.html>. Acesso em 22 de maio de 2016.

MOTTA, Alda Brito da. As velhas também. Ex æquo, n. 2 23, p. 13-21, 2011.

MOTTA, Alda Brito da. As dimensões de gênero e classe social na análise do envelhecimento. Cadernos PAGU, n. ${ }^{\circ}$ 13, p. 191-221, 1999. 
PAIVA, Sálvea de Oliveira Campelo e. Envelhecimento, saúde e trabalho no tempo do capital. 1.ed. São Paulo: Cortez, 2014.

PESQUISA DE EMPREGO E DESEMPREGO. Trabalho doméstico remunerado. Abr. 2015. Disponível em: < www.dieese.org.br/analiseped/2014/2014EmpregoDomestico.pdf >. Acesso em: 14 jun. 2015.

PINHEIRO, Luana Simões.; FONTOURA, Natália de Oliveira; e PEDROSA, Cláudia. Situação das trabalhadoras domésticas no país. IN: CASTRO, J. A.; ARAÚJO, H. E. (Org.) Situação das trabalhadoras domésticas no país. Situação social brasileira: monitoramento das condições de vida 2. Brasília: IPEA, 2012.

PINHEIRO, Luana Simões, LIMA JÚNIOR, Antônio Teixeira, FONTOURA, Natália de Oliveira, SILVA, Rosane da. Mulheres e trabalho: breve análise do período 2004-2014. Brasília, n. ${ }^{\circ}$ 24, IPEA, março de 2016.

PESQUISA NACIONAL POR AMOSTRA DE DOMICÍLIO (PNAD). 2013. Pela melhoria do emprego doméstico. 2013. Disponível em:

<http://www.domesticalegal.org.br/PNAD\%202013\%20-

\%20Brasil\%20com\%20comentarios.pdf>. Acesso em: 13 jun. 2016.

PESQUISA NACIONAL POR AMOSTRA DE DOMICÍLIO (PNAD). $1^{\circ}$ Trimestre de 2015. Disponível em:

<ftp://ftp.ibge.gov.br/Trabalho_e Rendimento/Pesquisa_Nacional_por_Amostra_de_Do micilios_continua/Trimestral/Comentarios/pnadc_201501_trimestre_comentarios.pdf $>$. Acesso em: 13 jun. 2016.

POLDI, Roberta Melo Vello; BORGES, Luiz Henrique; e DALBELLO-ARAÚJO, Maristela. Trabalho e saúde sob a ótica de domésticas e pedreiros do município da Serra, ES.

Cadernos de Psicologia Social do Trabalho. v.14, n. ${ }^{2}$, São Paulo, dez., 2011.

SA, Rosane Antunes de; WANDERBROOCKE, Ana Cláudia Nunes de Souza. Os significados do trabalho face ao envelhecimento para servidoras de uma instituição pública de ensino superior. Boletim de Psicologia, São Paulo, v. 66, n. ํ 145, p. 145-158, jul. 2016.

TAMANINI, Marlene. O processo saúde/doença das empregadas domésticas: gênero, trabalho e sofrimento. Revista de Ciências Humanas, Florianópolis, Edição Esp. Temática, p. 49-69, jan., 2000. 
WAJNMAN, Simone. Envelhecimento, participação laboral feminina e desigualdade de renda no Brasil. Brasília: IPEA; Belo Horizonte: CEDEPLAR/UFMG, 2001. (Texto para discussão, n. ${ }^{\circ}$ 788. Disponível em: < http://www.cepal.org/celade/noticias/paginas/5/27255/Wajnman.pdf >. Acesso em: 23 jun. 2016. 